\title{
Patterns of susceptibility in an outbreak of Bordetella pertussis: Evidence from a community-based study
}

\author{
David M Moore MDCM MHSc, Richard G Mathias MD FRCPC
}

\begin{abstract}
DM Moore, RG Mathias. Patterns of susceptibility in an outbreak of Bordetella pertussis: Evidence from a communitybased study. Can J Infect Dis 2002;13(5):305-310.
\end{abstract}

OBJECTIVE: To describe an outbreak of Bordetella pertussis and to assess which factors were associated with the development of clinical pertussis in children and adults during the outbreak. DESIGN: A case series was described to define the epidemiology of the pertussis outbreak. A school-based survey of children was used to measure the incidence of clinical pertussis over the previous six months. Vaccination records from the local public health facility were used to look at the relationship between age and vaccination parameters, and susceptibility to clinically diagnosed pertussis. A cross-sectional survey of teachers, parents and some hospital workers was used to assess these associations in adults. SETTING: An outbreak of pertussis in an isolated northern community in British Columbia.

POPULATION STUDIED: All children in the community who attend daycare, kindergarten or school, and their parents were surveyed. In addition, some health care workers and mothers of preschool children were surveyed.

MAIN RESULTS: A total of 31 suspected cases of pertussis were identified over a three-month period. Ninety per cent of the affected children who had available vaccination records had received four or five doses of pertussis vaccine. Sixty per cent of the town's 209 children returned completed surveys. Of these, $69 \%$ had available vaccination records. Thirty-six children (28\%) reported symptoms that fit the case definition for pertussis over the previous three months. Attack rates were highest for the group of children aged 10 to 14 years. In a multivariate logistic regression analysis, receiving prophylactic medication and an increased number of years from the last vaccine dose were found to be significant predictors for developing pertussis. Thirty-four per cent of the estimated 291 adults in the community returned completed surveys. The attack rate of pertussis in the adults was only $9 \%$. Being a member of the school staff and/or having a household contact with pertussis were significant predictors of developing pertussis.

CONCLUSIONS: Immunity to pertussis appears to wane during childhood. Peak susceptibility appears to be during early adolescence. Adults do not seem to be at greater risk than adolescents for developing the disease, but it seems unlikely that this is due to better immunity. Rather, it is probably related to a lower risk of exposure to pertussis and a lower rate of progression to symptomatic disease when adults are infected.

Key Words: Immunity; Pertussis; Vaccination

Résumé à la page suivante

Department of Health Care and Epidemiology, University of British Columbia, Vancouver, British Columbia

Correspondence and reprints: Dr Richard Mathias, Department of Health Care and Epidemiology, University of British Columbia,

5804 Fairview Avenue, Vancouver, British Columbia V6T 123. Telephone 604-822-4757, fax 604-822-4994, e-mail richard.mathias@ubc.ca Received for publication June 12, 2001. Accepted November 13, 2001 


\section{Modes de susceptibilité lors d'une éclosion de Bordetella pertussis : Données tirées d'une étude basée dans la communauté}

OBJECTIF : Décrire une éclosion de Bordetella pertussis et évaluer les fac-
teurs qui ont été associés au développement de la coqueluche clinique
chez des enfants et des adultes durant l'éclosion.
MODĖLE : Une série de cas a été décrite pour définir l'épidémiologie de
l'éclosion de coqueluche. Une enquête menée dans une école auprès d'en-
fants a été utilisée pour mesurer l'incidence de la coqueluche cli-nique au
cours des six mois précédents. Les dossiers de vaccination de l'établisse-
ment de santé publique locale ont été utilisés pour vérifier le lien entre
l'âge et les paramètres de vaccination, la susceptibilité à la coqueluche
diagnostiquée d'après les critères cliniques. Une enquête transversale
auprès des professeurs, des parents et de travailleurs de la santé a été util-
isée pour évaluer ces liens chez l'adulte.
CONTEXTE : Éclosion de coqueluche dans une communauté septentri-
onale isolée de la Colombie-Britannique.
POPULATION ÉTUDIÉE : Tous les enfants de la communauté ayant
fréquenté la garderie, la maternelle ou l'école et leurs parents ont été ques-
tionnés. En plus, certains travailleurs de la santé et certaines mamans
d'enfants d'âge préscolaire ont aussi été interrogés.
PRINCIPAUX RÉSULTATS : En tout, 31 cas soupçonnés de
coqueluche ont été identifiés au cours d'une période de trois mois.

$\mathrm{V}$ accination against Bordetella pertussis has resulted in a dramatic reduction in the incidence of this disease in Canada. Outbreaks of pertussis, however, still occur. While many outbreaks reported elsewhere occur in populations where vaccination rates have declined, many others occur in populations with high vaccination coverage $(1,2)$. This has not changed with the introduction of the acellular pertussis vaccine. The reasons for this are not clear, but waning immunity and the transmission of disease from adolescents and adults to younger children have been proposed as possible mechanisms $(3,4)$. An additional constraint in studying this problem is that there is no known level of antibody that can be shown to be protective against developing pertussis (5).

The idea of waning immunity has been challenged recently. De Serres and colleagues (6) found that the attack rates were the same in adolescent $(12 \%)$ and adult $(11 \%)$ household contacts of pertussis index cases. The authors (6) felt that this similar attack rate was more consistent with a decreasing proportion of susceptible subjects with age and with longlasting immunity. They did not suggest that this immunity comes solely from vaccination, but more likely from subclinical boosting from endemic disease. Clearly, this has implications as to the utility of introducing an adolescent booster dose to reduce further the incidence of disease in the population.

In May 2000, an outbreak of pertussis was reported in an isolated northern community in British Columbia. Pertussis outbreaks have been known to occur in three- to five-year cycles in British Columbia. The last such outbreak occurred in 1996 and 1997, and resulted in more than 1100 reported cases. Increased rates of pertussis transmission had already
Quatre-vingt-dix pour cent des enfants affectés dont on pouvait consulter les dossiers de vaccination avaient reçu quatre ou cinq doses de vaccin anti-coquelucheux; $60 \%$ des 209 enfants de la petite municipalité ont retourné les questionnaires complétés. Parmi ces enfants, 69 \% avaient des carnets de vaccination à jour que l'on pouvait consulter, 36 enfants (28\%) ont signalé des symptômes qui concordaient avec la définition de la coqueluche au cours des trois mois précédents. Les taux ont été plus élevés chez les enfants de 10 à 14 ans. Dans le cadre d'une analyse de régression logistique multivariée, le fait d'avoir reçu un médicament prophylactique et un nombre supérieur d'années séparant la dernière dose de vaccin, se sont révélés être des facteurs de prévisibilité significatifs à l'égard de la coqueluche. Trente-quatre pour cent des 291 adultes interrogés dans la communauté ont retourné leurs questionnaires dûment complétés. Le taux de coqueluche chez les adultes a été de $9 \%$ seulement. Le fait d'appartenir au personnel de l'école ou d'avoir un contact coquelucheux à la maison se sont révélés des facteurs de prévisibilité significatifs à l'égard de la coqueluche.

CONCLUSION : L'immunité contre la coqueluche semble diminuer durant l'enfance. La période de plus grande susceptibilité se trouve au début de l'adolescence. Les adultes ne semblent pas être exposés à un risque plus grand que les adolescents à l'égard de la maladie, mais il paraît peu probable que cela soit attribuable à une meilleure immunité. Le phénomène s'explique probablement par un risque moindre d'exposition à la coqueluche et un taux plus faible de progression de la symptomatologie lorsque les adultes sont infectés.

been reported throughout the province since January 2000 (British Columbia Centre for Disease Control, internal report). By mid-May 2000, nearly 400 cases had been reported to the British Columbia Centre for Disease Control. Rates of infection were highest among young adolescents (aged 10 to 14 years), followed by older children (aged seven to nine years). The Northwest Coastal Health Services Society (the region that includes the town of Stewart) was not among those health regions that had previously reported increased numbers of cases.

The town of Stewart, which has a population of approximately 500 people, has one health centre for both curative and preventive care, and is more than $150 \mathrm{~km}$ from the nearest settlement (excluding the hamlet of Hyder, Alaska, which is only $1.6 \mathrm{~km}$ away). There are three schools - a public primary school, a public secondary school and a small, private Christian school. The local health region and the Department of Health Care and Epidemiology at the University of British Columbia initiated an investigation of the pertussis outbreak in Stewart. It was thought that the relative isolation of the community and its small size would allow investigators to see whether immunization status, age and the length of time from the last vaccine dose would significantly affect disease attack rates. It was hoped that vaccination records for most of the town's children could be verified and then compared with the results of a school-based survey for pertussis-like symptoms. As well, a survey of adults was undertaken to determine whether symptoms also occurred in this susceptible group, and whether this was related to recalled vaccination history. Disease control measures (7), including erythromycin prophylaxis of close contacts of index cases and enhanced sur- 
veillance among symptomatic individuals, had already been implemented before the present study was undertaken and were not interrupted during the course of the study.

\section{Description of the outbreak}

\section{METHODS}

A list of suspected cases was obtained from the public health records in Stewart. Notifiable disease reports were reviewed to record the age, date of birth, onset of symptoms, duration of symptoms, erythromycin use, whether nasopharyngeal swabs were taken, and the results of culture and polymerase chain reaction (PCR) investigations. Verbal consent to review clinical records, confirm this information and obtain added information on symptomatology was obtained by telephone from all subjects. Based on these results, subjects were classified as either confirmed cases, suspect cases, or nonspecific cases, based on definitions outlined by the Laboratory Centre for Disease Control of Health Canada (8). Definitions were as follows:

- Confirmed case: Laboratory confirmation or a clinical case with an epidemiological link to a laboratory confirmed case.

- Clinical case: Cough lasting longer than two weeks, plus one or more of paroxysmal cough, cough ending in vomiting or apnea, or inspiratory whoop.

- Suspect case: Paroxysmal cough or whoop, or cough ending in gagging or apnea.

- Nonspecific case: Respiratory illness with cough, not meeting another definition.

All available vaccination records on file in the Stewart Health Centre were reviewed for cases and noncases. The number of pertussis doses, date of last dose and time from last dose were recorded.

School-based survey: A single-page questionnaire was given to all students and staff at the primary and secondary schools. School staff and secondary students were asked to fill out the questionnaire and return it before leaving school for the day. Primary school students were given the questionnaire to take home for their parents to complete on their behalf. In addition, each student was given two questionnaires for their parents. Questionnaires for children, staff and parents were also given out at the community daycare centre and the Christian school. The public health nurse conducted telephone interviews of approximately 10 mothers of children younger than five years of age who were registered with the health centre, to obtain information about their children.

Information was collected on the history of having had a diagnosis of whooping cough, and the history of a chronic cough in the previous six months and its association with other symptoms. Subjects were also asked about contact with other possible cases and whether they had received

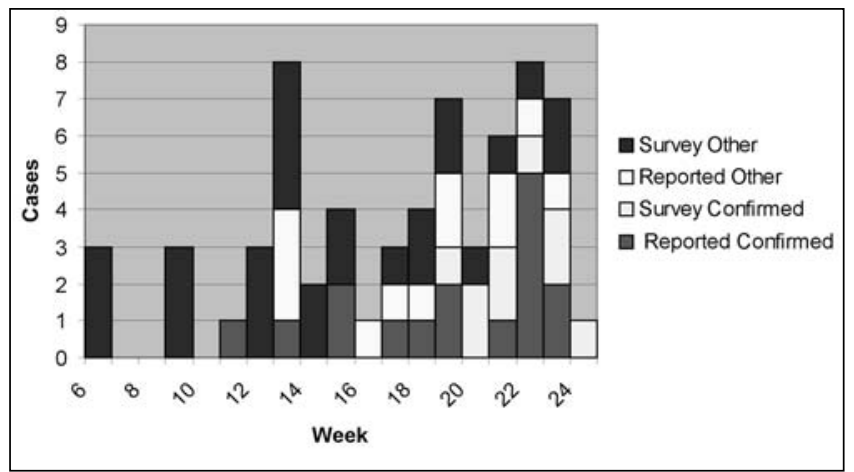

Figure 1) The epidemic curve for the 28 cases for which date of symptom onset could be estimated for an outbreak of Bordetella pertussis

prophylactic medication. Adults were also asked about whether they were vaccinated as children, whether they or their parents ever refused vaccination and whether they had lived in Canada before the age of five years. Some of the health centre staff also filled out questionnaires. Respondents were then classified as suspect cases or clinical cases. Available vaccination records in the health centre were reviewed for all children who returned a questionnaire. The records included the number of pertussis vaccine doses and the date of the last dose.

Logistic regression analysis of both the adult and child surveys was performed using the presence or absence of a positive case definition as the outcome variable. Those variables that were found to be significant in a univariate analysis were then combined in a multivariate regression analysis to yield the final model.

\section{Description of the outbreak}

\section{RESULTS}

Thirty-one potential cases of pertussis were identified by the physicians in Stewart during the period of mid-May to mid-June 2000. Of these, 16 were classified as confirmed cases, nine as suspect cases and six as nonspecific cases. Figure 1 shows the epidemic curve for the 28 cases for which date of symptom onset could be estimated. While the numbers are small, there is a suggestion of two peaks in disease onset; one in late March 2000 and the other in late April 2000. Table 1 shows the identified cases, broken down in terms of age group. Most cases occurred in the five to nine and 10 to 14 years of age groups, although the latter group had more subjects that met the case definition. No cases were identified in children younger than five years of age. It is also worth noting that no children younger than five years of age were hospitalized during this period.

Fifteen of the 31 identified cases had vaccination records available at the health centre. Those cases represented $62.5 \%$ (15 of 24) of the school-aged children. Of those whose records could be verified, there was little difference between the age groups in terms of the availability of vaccination records. Thirteen of 15 (87\%) had received four or five doses of pertussis vaccine. None had received less than three doses. Only one subject had received his or her last 
TABLE 1

Cases by age group

\begin{tabular}{|c|c|c|c|c|c|c|c|c|}
\hline \multirow{2}{*}{$\begin{array}{l}\text { Age } \\
\text { (years) }\end{array}$} & \multicolumn{4}{|c|}{ Reported cases } & \multicolumn{4}{|c|}{ School survey } \\
\hline & Confirmed & Suspect & Nonspecific* & Total & Confirmed & Clinical & Suspect & Total \\
\hline$<1$ & 0 & 0 & 0 & 0 & & & & \\
\hline 1 to 4 & 0 & 0 & 0 & 0 & 0 & 1 & 0 & 1 \\
\hline 5 to 9 & 6 & 1 & 3 & 10 & 4 & 5 & 1 & 10 \\
\hline 10 to 14 & 5 & 4 & 1 & 10 & 2 & 11 & 2 & 15 \\
\hline 15 to 19 & 1 & 1 & 1 & 3 & 1 & 7 & 0 & 8 \\
\hline 20 to 24 & 3 & 0 & 1 & 4 & & & & \\
\hline$>24$ & 1 & 1 & 0 & 2 & & & & \\
\hline
\end{tabular}

*Individuals who were ill but did not meet the case definitions

dose of pertussis vaccine within the previous three years, the time frame in which the full effects of the vaccine should be maintained. Nine of the identified cases who had vaccination records were between three and 10 years from the time of their last vaccine dose, and only three had received their last vaccine dose more than 10 years earlier.

Cross-sectional survey of children: Surveys for 51 of 61 (83.6\%) secondary school students and 56 of 86 surveys $(65 \%)$ for kindergarten and primary school-aged children were completed. Because the questionnaires were distributed on the last day of school at the Christian school, only one of 12 children returned the completed questionnaire. The daycare distribution and telephone surveys collected information on 17 of the approximately 50 (34\%) children younger than five years of age. Overall, 125 of 209 (59.8\%) children in the town returned completed questionnaires.

Thirty-six respondents gave a history of having had a cough consistent with a case definition of pertussis. This represented $29 \%$ of respondents. Only nine of the 36 were confirmed cases identified by the public health records at the health centre. An additional five of the confirmed cases did not return completed questionnaires.

Figure 1 shows the date of symptom onset for the 36 respondents who reported pertussis-like symptoms. The same double peak that was observed in those identified through public health records is seen; one in March and one in May. Table 1 shows the age of those who reported pertussis-like symptoms. Only one positive history was reported in a child younger than five years of age. The number of positive responses increased from 10 in the five to nine years of age group to 15 in the 10 to 14 years of age group. These represent attack rates of $27 \%$ and $46 \%$ of the respective age groups of those who returned completed questionnaires.

Vaccination records were found for 24 of the 36 positive respondents (67\%) and 86 of 125 children overall (69\%). Only 25 of the $51(49 \%)$ secondary school students had available vaccination records, while 43 of the 56 (76.8\%) elementary and kindergarten students had available records.

A logistic regression analysis was run to test the hypothesis that the likelihood of developing pertussis-like symptoms was related to the number of pertussis vaccine doses received, the number of years since the last dose was given, the age of the respondent, whether the respondent had contact with a suspected case, or the use of erythromycin prophylaxis. A history of contact with a suspected case, the use of prophylaxis and the number of years since the last vaccine dose were all found to be significant at $\mathrm{P}<0.05$. Neither age nor total number of doses of vaccines received was found to be a significant predictor of pertussis-like symptoms. An interaction term made up of age and number of years since vaccination was also not found to be significant.

Bivariate correlations were run for all variables to check for possible colinearity. Several variables had significant correlations at $\mathrm{P}<0.05$. However, only the correlation between age and time since last dose had coefficient values greater than 0.6. This likely explains why there were different attack rates for the different age groups, even though age itself is not a significant predictor of developing symptoms. Age is really only a marker for the number of years since the last vaccine dose.

Variables that were found to be significant in the univariate analysis were then combined in a multivariate model. The final model included only prophylaxis and years since last vaccine. Because the coefficient for prophylaxis is not negative, it is likely that this is really only a proxy marker for having had contact with a known case. It turns out to be a better marker for contacts than asking whether someone at home was told that they had pertussis or had a pertussislike cough.

Adult cross-sectional survey: Completed surveys were returned from 99 adults. The estimated adult population of the town was 291, so this represented $34 \%$ of the total adult population. Because the respondents were either parents of school-aged children, or school or hospital staff, they were 
more likely to have been exposed to the age groups most affected by the outbreak. Nine of the 99 respondents $(9.1 \%)$ gave a history that was consistent with pertussis infection in the previous six months. As well, there were not large differences in the age groups of the affected subjects, except that nearly all were younger than the age of 50 years.

Univariate analysis was completed with each explanatory variable except hospital staff, because there were only three staff members who completed surveys. Being a school employee and/or having a household contact with a suspected case were significant predictors of reporting pertussis-like symptoms in the previous six months. Only five subjects reported not being fully vaccinated, and only one subject reported vaccine refusal. Fifteen subjects had lived outside of Canada before the age of five years. The final multivariate model included being a school employee and having had contact with a pertussis case in the model.

\section{DISCUSSION}

Twenty-four of 31 cases identified by the physicians in Stewart met the case definitions for either confirmed or suspect cases for pertussis. There appear to have been two peaks to the outbreak, one in late March 2000 and the other in May 2000. This shows good correlation with the results from the school survey in children, which also showed this double peak. Twenty-three cases were identified in school-aged children through public health records, whereas 36 cases were identified through the survey. A reporting bias would normally be expected to pick up nearly all the affected subjects in the survey, but at least five of the confirmed cases did not return a survey, suggesting that there may have been additional unreported cases in the community. Combining the two sources of data suggests that there may have been 41 cases of pertussis infection in children, of which only 23 (56\%) were identified and reported to public health officials.

While the school survey did reveal a trend toward higher attack rates in the 10 to 14 years of age group, regression analysis showed that age itself was not a significant predictor of self-reporting of pertussis-like symptoms. What was most significant was the number of years since the last dose of vaccine. This was consistent with the hypothesis that vaccine-induced immunity wanes over time, leading to increased susceptibility in adolescents and adults. While very few affected children were found to have a documented time from last vaccine dose of more than 10 years, this likely reflects the decreasing likelihood of finding the vaccination records in older children. This trend toward increased rates of disease in 10- to 14-year-olds is consistent with other outbreaks in the province of British Columbia in 2000 (British Columbia Centres for Disease Control internal report).

The number of vaccine doses received did not seem to be significant in predicting pertussis-like symptoms. This was likely because all children whose vaccination records could be checked had received at least three doses, the number that is believed to be needed to develop maximal immunity.

Only nine of the 99 respondents $(9.1 \%)$ to the adult survey reported having had pertussis-like symptoms over the previous six months. This was much lower than the attack rate in teenagers. The lower attack rate found in adults in this study contrasted with the study in Quebec (6), which found no difference in secondary attack rates between adolescents and adults. It is quite possible that the adolescents in the present study were at higher risk for developing pertussis than were the adults, because they could be potentially exposed to many infectious contacts at school each day. In the Quebec study, adolescents and adults were equally exposed to index cases of pertussis in the home and, thus, had equal risk for developing the disease. If immunity does wane over a period of three to 10 years, it is possible that it reaches its lowest level in the mid-teens. There may be no apparent difference in susceptibility to pertussis between adolescents and adults because both groups already experience low levels of protection. They may not be at equal risk of exposure to infection, however.

Another factor leading to a lower incidence of clinical disease in adults may be simply a decreased susceptibility to developing symptoms. It is interesting to note that, toward the later stages of the outbreak, when community and professional awareness was at its peak, at least two adults were found to be PCR-positive for pertussis when they did not have any clinical manifestations other than a mild cough of less than one week's duration. Thus, there may be more pertussis infections in the adult population, but a smaller proportion of adults will develop symptoms.

Vaccination history and residency during childhood had no significant effect on the reporting of pertussis-like symptoms in adults. This was probably due to the combination of too few defined cases and almost no variability to the responses to these questions in the survey. Working in a school or having a household contact were the only identifiable risk factors for developing illness.

These conclusions must also take into account the limitations of this study. Because only $60 \%$ of children and $34 \%$ of adults returned completed questionnaires, there was a possibility of a reporting bias leading to an overestimation of disease rates. However, in the child survey, five cases that had been reported to public health did not return completed surveys. This would indicate that over-reporting of symptoms in those who returned surveys probably did not occur. If a reporting bias did occur in the adult survey, we would expect the final attack rates to be even lower than those reported here, and would not alter the final conclusions. The study was designed to ensure that those individuals who had the greatest likelihood of exposure to pertussis were surveyed. Thus, focusing on school-aged children, school employees and adults with children who attend school was an appropriate way to select for those at highest risk of developing the disease. The actual rates of disease, therefore, may be overestimates, but the associations between the various risk factors should be valid. 


\section{CONCLUSIONS}

The present study shows, once again, that adolescents and older children are often the most affected by an outbreak of pertussis. Many adults may also become infected, but may not develop significant symptoms. Vaccine-induced immunity seems to wane from childhood to adolescence, but does not appear to wane further into adulthood. These findings suggest that adding an additional booster dose of acellular pertussis vaccine for adolescents may be helpful in further reducing the development of clinical disease in the community.

\section{REFERENCES}

1. Christie CD, Marx ML, Marchant CD, Reising SF. The 1993 epidemic of pertussis in Cincinnati - resurgence of disease in a highly immunized population of children. N Engl J Med 1994;331:16-20.
2. He Q, Vijanen MK, Arvilommi H, Aittanen B, Mertsola J. Whooping cough caused by Bordetella pertussis and Bordetella parapertussis in an immunized population. JAMA 1998;280:635-7.

3. Jenkinson D. Duration of effectiveness of pertussis vaccine: Evidence from a 10 year community study. BMJ 1988;296:612-4.

4. Farizo KM, Cochi SL, Zell ER, Brink EW, Wassilak SG, Patriarca PA. Epidemiological features of pertussis in the United States, 1980-1989. Clin Infect Dis 1992;14:708-19.

5. Pertussis vaccine. In: National Advisory Committee on Immunization, eds. Canadian Immunization Guide, 5th edn. Ottawa: Canadian Medical Association, 1998:133-9.

6. De Serres G, Shadmani R, Duval B, et al. Morbidity of pertussis in adolescents and adults. J Infect Dis 2000:182:174-9.

7. National Advisory Committee on Immunization and Canadian Paediatric Society. Statement on management of persons exposed to pertussis and pertussis outbreak control. CMAJ 1995;152:712-6.

8. National Advisory Committee on Immunization. Statement on adult/adolescent formulation of combined acellular pertussis, tetanus and diphtheria vaccine. Can Commun Dis Rep 2000;26:1-7. 


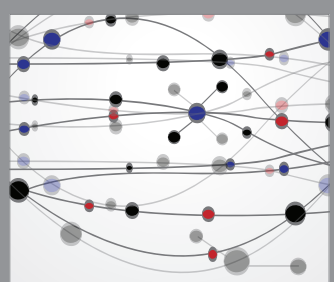

The Scientific World Journal
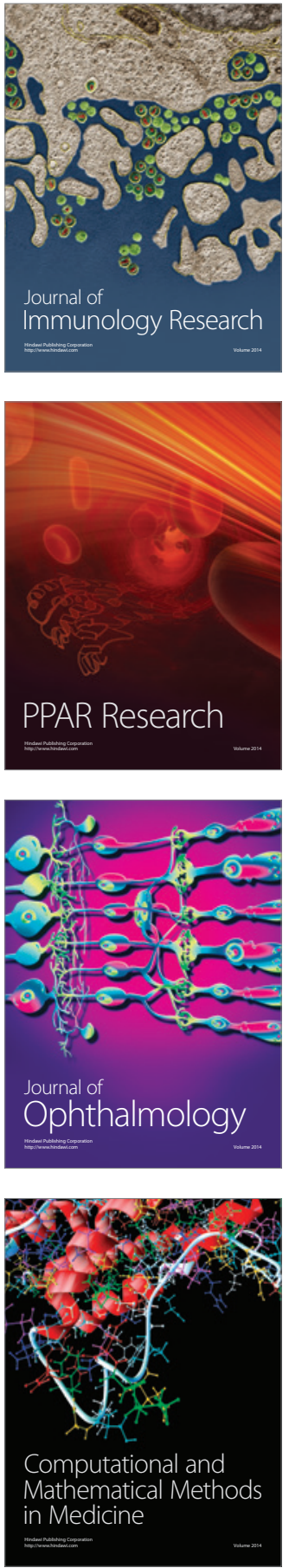

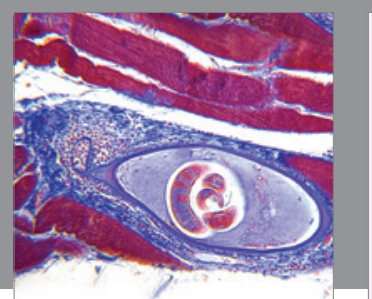

Gastroenterology Research and Practice

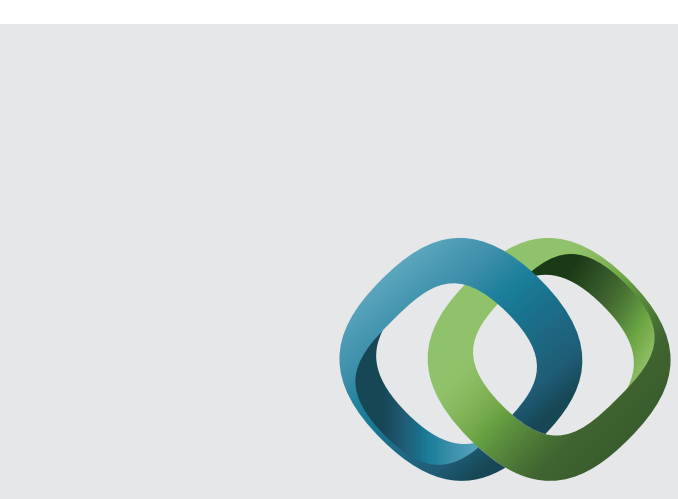

\section{Hindawi}

Submit your manuscripts at

http://www.hindawi.com
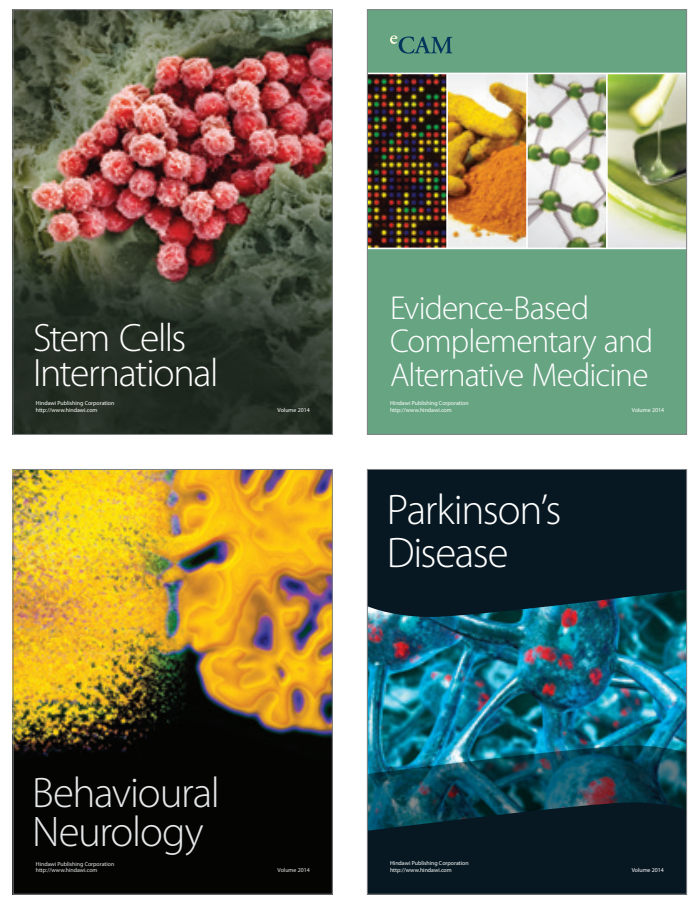
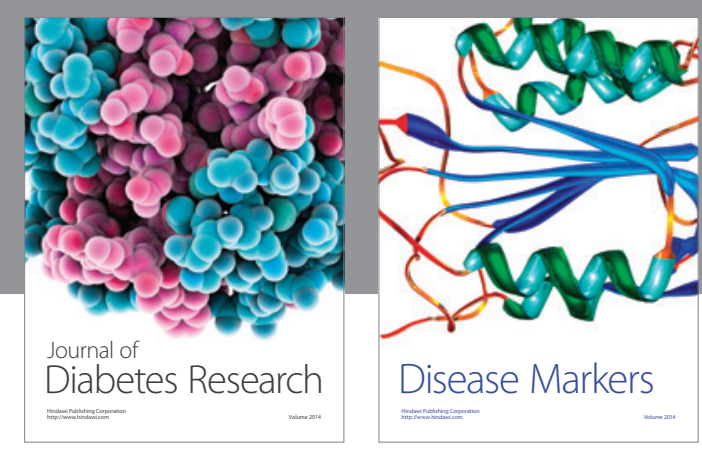

Disease Markers
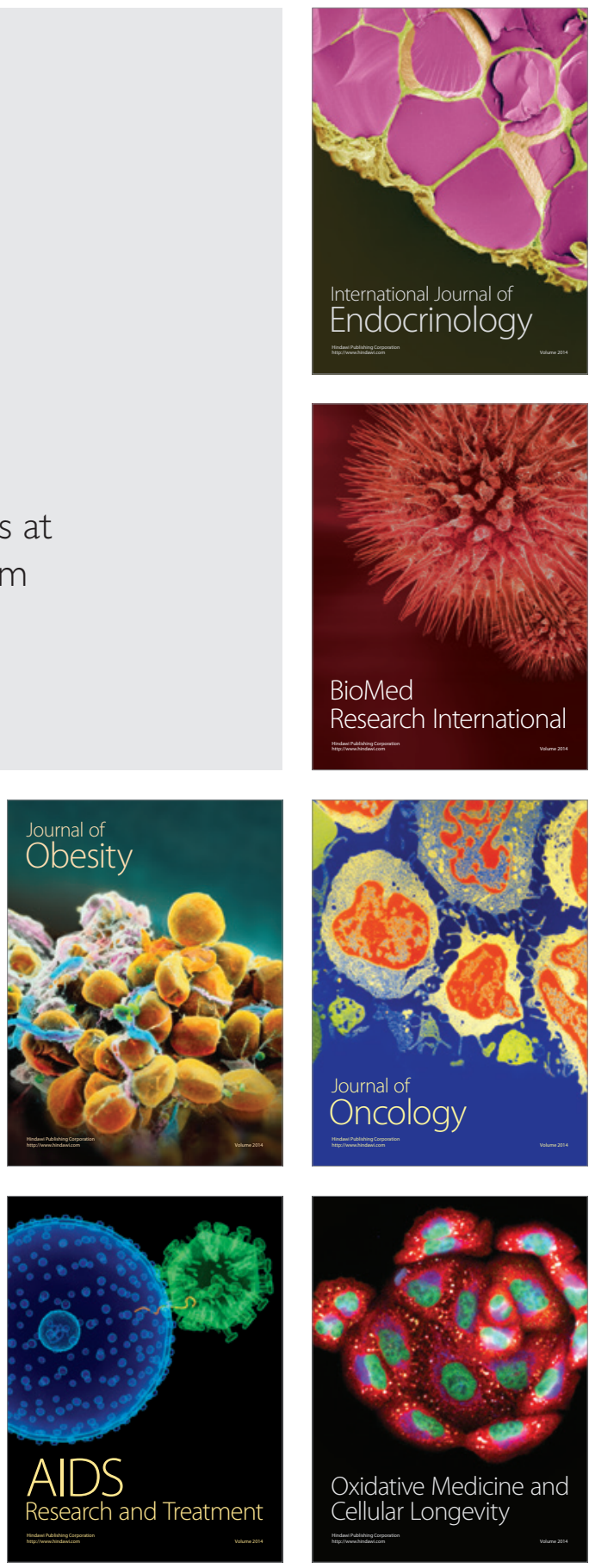